\title{
Uncommon Differential Diagnosis of Acute Right-sided Abdominal Pain - Case Report
}

\author{
Cédric Kwizera', Benedikt Wagner², Johannes B. Wagner ${ }^{3}$, Călin Molnar ${ }^{1}$ \\ 1 Department of Surgery, Emergency County Hospital, Târgu Mureș, Romania \\ 2 Student, Faculty of General Medicine, University of Medicine, Pharmacy, Science and Technology, Târgu Mureș, Romania \\ 3 Department of General, Abdominal and Endovascular Surgery, District Hospital Landsberg am Lech, Germany
}

\section{CORRESPONDENCE}

\section{Cédric Kwizera}

Str. Gheorghe Marinescu nr. 50

540136 Târgu Mureș, Romania

Tel: +40 729937393

E-mail: cedrickwizera.md@gmail.com

\section{ARTICLE HISTORY}

Received: February 22, 2019

Accepted: March 27, 2019
Benedikt Wagner - Str. Gheorghe Marinescu nr. 38 540139 Târgu Mureș, Romania. Tel: +40 265215551 Johannes B. Wagner - Bürgermeister-Dr.-HartmannStraße nr 50,86899 Landsberg am Lech, Germany. Tel: +49 81913330

Călin Molnar • Str. Gheorghe Marinescu nr. 38, 540139 Târgu Mures, Romania. Tel: +40 265215551

\begin{abstract}
The appendix is a worm-like, blind-ending tube, with its base on the caecum and its tip in multiple locations. Against all odds, it plays a key role in the digestive immune system and appendectomy should therefore be cautiously considered and indicated. We report the case of a 45-year-old male with a known history of Fragile-X syndrome who presented to the emergency department with intense abdominal pain and was suspected of acute appendicitis, after a positive Dieulafoy's triad was confirmed. The laparoscopic exploration showed no signs of inflammation of the appendix; nonetheless, its removal was carried out. Rising inflammatory laboratory parameters led to a focused identification of a pleural empyema due to a tooth inlay aspiration. Our objective is to emphasize the importance of a thorough anamnesis, even in cases of mentally impaired patients, as well as to highlight a rare differential diagnosis for appendicitis. Acute appendicitis is an emergency condition that requires a thorough assessment and appropriate therapy. Clinical examinations are important, but in this particular case, imaging methods had a much more important role in establishing the right treatment approach. Furthermore, the signs of acute appendicitis are mimicked by several medical conditions including respiratory tract infections.
\end{abstract}

Keywords: appendicitis, pleural empyema, differential diagnosis, tooth inlay aspiration

\section{INTRODUCTION}

The appendix or vermiform process is a worm-like, blind-ending tube connected to the caecum, about $2 \mathrm{~cm}$ beneath the Bauhin valve. Its average dimensions are 7-8 $\mathrm{mm}$ wide and $9 \mathrm{~cm}$ long, but its length can range from 2 to $20 \mathrm{~cm}$, the longest ever recorded appendix being $26 \mathrm{~cm}$ long, discovered postmortem in a 72-year-old Croatian patient (Guinness World Record 2006). Its base is attached to the cecum, but the position of its tip can vary, as it can be retrocecal, subcecal, pre-ileal, retroileal, pelvic, or ectopic. ${ }^{1}$ The appendix has long been considered worthless due to the absence of noticeable reactions post appendectomy, hence the assumption of its vestigial characteristics. ${ }^{2}$ Nevertheless, William Parker et al. suggested that it may act as a storage unit of beneficial microbiome, activated especially after the reduction of normal intestinal bacteria following infectious 


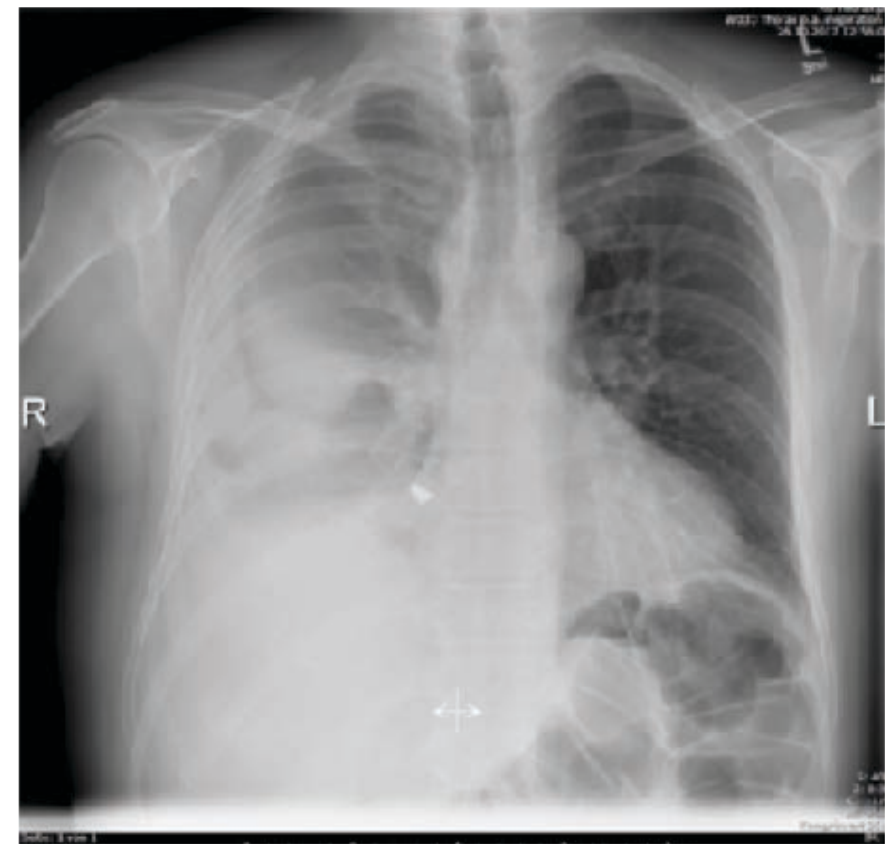

FIGURE 1. Thoracic X-ray, coronal view: aspect of encapsulated, presumably interlobular effusion, component of the right lung with basal ventilatory dysfunction. Unidentifiable, radiopaque, foreign body of approximately $1.3 \mathrm{~cm}$ in diameter, in the right cardiophrenic angle.

diseases, ${ }^{3}$ because the immune system participates in the formation of the beneficial microbiome due to the location of the appendix and its histological structure with immune tissues. ${ }^{4}$ Research has shown that patients were four times more prone to a recurrent Clostridium difficile colitis following an appendectomy. ${ }^{5}$ Its structure contains B cells, extra-thymic T cells along with lymphatic vessels, participates in the elimination of gastrointestinal waste, stopping pathogens and assuring an early immunological defense. ${ }^{6}$ In most of the cases, pain located in the right iliac fossa is usually a sign of acute appendicitis. The present case report is about a mentally impaired patient admitted and inadvertently operated for acute appendicitis. Subsequently, he was diagnosed and treated for pleural empyema due to a foreign body aspiration.

\section{CASE PRESENTATION}

A 45-year-old male presented to the emergency department with severe abdominal pain. Due to his mental impairment with a known diagnosis of Fragile X-syndrome, collecting his past medical record was heavily impeded, and nothing else - besides a positive Dieulafoy's triad - was determined. Therefore, an acute appendicitis was suspected. An ultrasonography examination was impossible, due to the lack of compliance. Following the informed consent

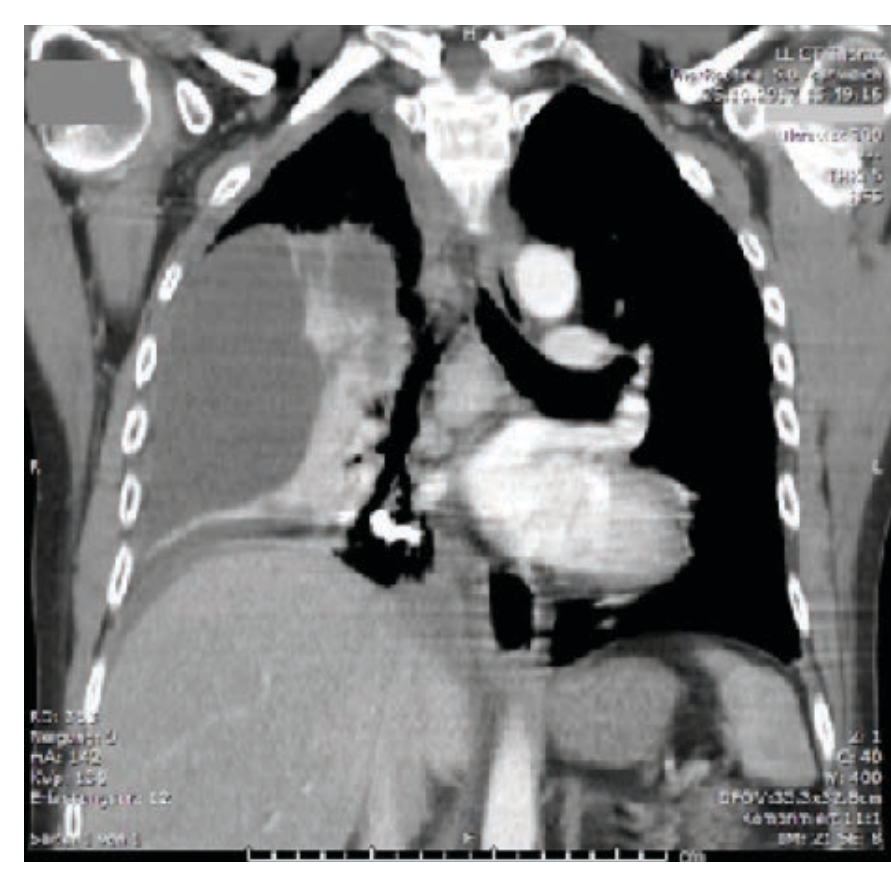

FIGURE 2. Thoracic CT, coronal view: expanding serous pleural effusion on the right side (no distinct empyema criteria), with adjacent partial ventilatory dysfunction, particularly in the lower right lobe. Presumably intrabronchial aspirate lying in a proximal segmental bronchus.

of his caregiver and a laboratory evaluation which revealed a CRP of $3.41 \mathrm{mg} / \mathrm{dL}$ and leucocytes of $15.3 \times 10^{\wedge} 3 / \mathrm{L}$, a laparoscopic exploration was performed on the same day of admission. Although the appendix presented no major signs of inflammation or other pathological characteristic upon laparoscopic inspection, it was removed in order to exclude neurogenic appendicopathy. The histologic examination showed no signs of malignancy and no significant inflammatory infiltrates. The initial postoperative course proved to be without any complications and without signs of wound infection. Postoperative oral feeding also took place without complications. Nevertheless, on the first day following surgery, the laboratory revealed raising inflammatory parameters such as CRP of $34.09 \mathrm{mg} / \mathrm{dL}$ and leucocytes of $18.2 \times 10^{\wedge} 3 / \mathrm{L}$, which led to further investigation of the patient. Thoracic X-ray (Figure 1) raised the suspicion of a foreign body in the area of the inferior lobe of the right lung and of an incipient pleural empyema.

To complete the records of medical findings, a computed tomography (CT) scan of the thorax was performed, which confirmed the suspicion (Figure 2).

Thus, bronchoscopy and video-assisted thoracoscopic surgery (VATS) was indicated. Under general anesthesia and intubated with a double-lumen tube, a golden tooth inlay was retrieved from the segmental bronchus of the right inferior lobe with the aid of the bronchoscope. Dur- 

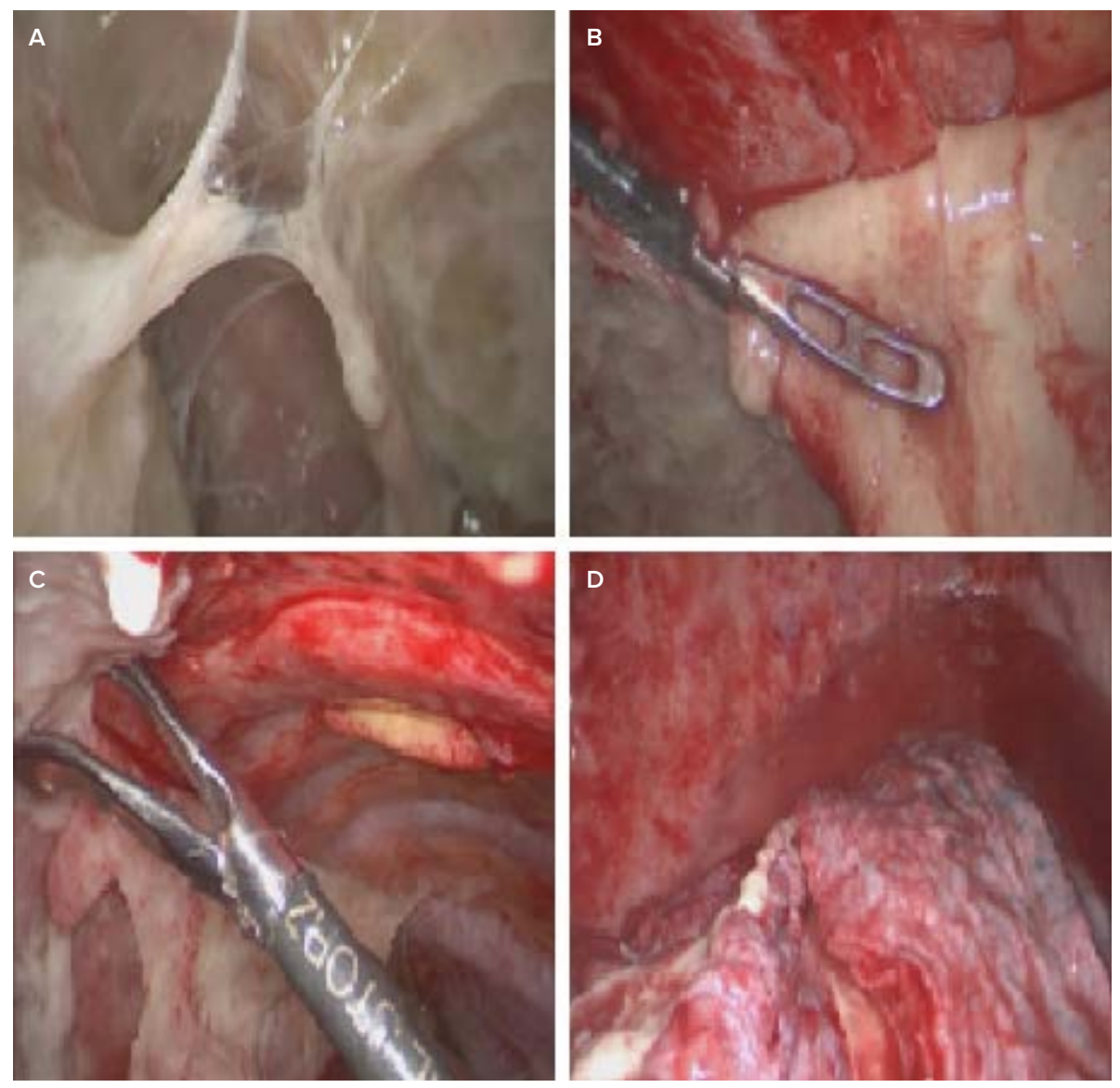

FIGURE 3. VATS. A - empyema before decortication; B, C - empyema during decortication; $\mathbf{D}$ - finalized decortication

ing the first access into the thoracic cavity, putrid liquid was emptied. On investigation of the pleural cavity, a mobile fibrous block covering the right lung was observed, and consecutively a progressive decortication of the lung took place (Figure 3).

The patient was monitored postoperatively in the intensive care unit. The postoperative course henceforward was without any complications, the drainages were removed in time. Under antibiotic therapy with Meropenem, the inflammatory laboratory parameters regressed, in the end the serum level of CRP was $3.90 \mathrm{mg} / \mathrm{L}$ and leucocytes were $10.8 \times 10^{\wedge} 9 / \mathrm{L}$. Also, the right lung showed no signs of pneumothorax or ventilatory dysfunctions on the control X-ray. The patient was discharged after 12 days of hospitalization with good general status, both clinically and biologically. Three months later, he is free of symptoms concerning his pulmonary situation.

\section{DISCUSSION}

McBurney's sign, characterized by a deep tenderness in the right iliac fossa, contributes significantly to the diagnosis of acute appendicitis. ${ }^{7}$ The pain felt in the epigastrium upon continuous pressure over McBurney's point is called Aaron's sign..$^{8}$ In practice, there are a number of clinical signs that indicate acute appendicitis: obturator sign, psoas sign, Rovsing's sign, Blumberg's sign, Markle's sign. ${ }^{9-11} \mathrm{Howev}-$ er, these clinical signs are encountered in a minority of patients. The typical signs of acute appendicitis are: generalized abdominal pain, more intense in the umbilical region, inappetence, nausea, vomiting, leukocytosis and fever. Afterwards, the pain installs in the lower right quadrant/ fossa (same situation in patients with situs inversus with a left lengthy appendix). Georges Paul Dieulafoy described his famous triad in acute appendicitis: hypersensitivity of the skin, tenderness, and muscular contraction at McBurney's point. ${ }^{12}$ However, there are several atypical signs for acute appendicitis, with only pain as described above and peritonitis, which requires further investigations such as imaging techniques. ${ }^{13}$ Our patient presented with generalized abdominal pain and elevated inflammatory blood tests, but due to his mental impairment, we could neither gather enough details for an appropriate history nor perform imaging investigations, thus the case was labeled as 
an atypical acute appendicitis. A C-reactive protein level higher than $1 \mathrm{mg} / \mathrm{dL}$ is often encountered in acute appendicitis, and if leukocytosis with neutrophilia is present, it could indicate a gangrenous appendicitis at onset. A negative predictive outcome of $97-100 \%$ for acute appendicitis is encountered in adult patients with clinical symptoms but with a normal level of C-reactive protein. ${ }^{14,15} \mathrm{CT}$ scan with oral contrast is the most used diagnostic tool in atypical appendicitis. However, another primary tool for diagnosis is ultrasound imaging. The American College of Emergency Physicians recommends the use of ultrasound for the confirmation of acute appendicitis and CT scan for its exclusion. ${ }^{16}$ The emergency assessment of acute appendicitis is the following: nil per os for patients with acute appendicitis suspicion, intravenous access for fluids and preoperative antibiotic prophylaxis using broad spectrum antibiotics for gram-negative and anaerobic germs, category A or B antibiotics in pregnant women and carbapenems in patients who are allergic to penicillin. In our case, a single shot of cefuroxime/metronidazole was administered. Overall, the surgical approach is the gold standard method of care in acute appendicitis. A number of clinical conditions can mimic the signs and/or symptoms of acute appendicitis such as: pelvic inflammatory disease (PID) or tubo-ovarian abscess, endometriosis, ovarian cyst or torsion, ureterolithiasis and renal colic, degenerating uterine leiomyoma, diverticulitis, Crohn's disease, colon carcinoma, rectus sheath hematoma, cholecystitis, bacterial enteritis, mesenteric adenitis and ischemia, omental torsion, biliary colic, renal colic, urinary tract infection (UTI), gastroenteritis and enterocolitis. ${ }^{17}$ Other clinical conditions that should be taken into account are stump appendicitis after an incomplete appendectomy, typhlitis, epiploic appendagitis, and, last but not least, an extra-abdominopelvic cause in which pain is projected into the abdomen. ${ }^{18,19}$ Acute appendicitis is often misdiagnosed as gastroenteritis and upper or lower respiratory infection in children; the rate of misdiagnosis decreases with age, ranging from almost $100 \%$ in children aged 3 and below to $15 \%$ in teenagers. ${ }^{20}$ Although our case is about an adult patient, it was later on that a respiratory infection was diagnosed, leading to the correct treatment of his condition.

\section{CONCLUSION}

Acute appendicitis is an emergency condition that requires a thorough assessment and an appropriate therapy consisting in a medico-surgical approach, with classic or laparoscopic surgery being the gold standard method of care. In some cases, certain conditions can mimic the signs and/or symptoms of acute appendicitis, leading to a non-negligi- ble number of misdiagnoses, which can be life-threatening. In mentally healthy patients, a series of elements are required for a correct diagnosis and treatment: a thorough clinical history, which must include information regarding the onset and the evolution of symptoms until admission to the hospital, as well as information regarding the intake of drugs; physical examination, the most important part being palpation; and last but not least, paraclinical investigations such as laboratory tests (complete blood count, Creactive protein) and imaging investigations (ultrasound and CT scan, especially in cases of atypical acute appendicitis). In some cases, several rare conditions should be taken into account for abdominal pain, especially if inflammation signs persist postoperatively.

\section{CONFLICT OF INTEREST}

Nothing to declare.

\section{REFERENCES}

1. Collins DC. 71,000 human appendix specimens. A final report summarizing forty years study. Am J Proctol. 1963;14:365-381.

2. Sarkar A. Congenital absence of the vermiform appendix. Singapore Med J. 2012;53:e189-191.

3. Bollinger RR, Barbas A, Bush E, Lin S, Parker W. Biofilms in the large bowel suggests an apparent function of the human vermiform appendix. J Theor Biol. 2007;249:826-831.

4. Sonnenburg JL, Angenent LT, Gordon JI. Getting a grip on things: how do communities of bacterial symbionts become established in our intestine? Nat Immunol. 2004;5:569-573.

5. Dunn R. Your Appendix Could Save Your Life. Sci Am. 2012;306:22-22.

6. Zahid A. The vermiform appendix: not a useless organ. Journal of the College of Physicians and Surgeons Pakistan. 2004;14:256-258.

7. Bevan P. Diagnosis Of Acute Appendicitis: Three Physical Signs. The Lancet. 1961;277:404

8. Wyer P. Review: symptoms, signs, and lab tests have moderate accuracy for detecting appendicitis in children. Evid Based Med. 2008;13:23-23.

9. Dave WW. Rovsing's sign. Br Med J. 1956;2:28-30.

10. Alvarado A. How to improve the clinical diagnosis of acute appendicitis in resource limited settings. World J Emerg Surg. 2016;11:16.

11. Markle GB. Heel-drop jarring test for appendicitis. Arch Surg. 1985;120:243

12. Karamanou M, Fiska A, Demetriou T, Androutsos G. Georges-Paul Dieulafoy (1839-1911) and the first description of "exulceratio simplex". Ann Gastroenterol. 2011;24:188-191.

13. Debnath J, George RA, Ravikumar R. Imaging in acute appendicitis: What, when, and why?. Med J Armed Forces India. 2016;73:74-79.

14. de Carvalho BR, Diogo-Filho A, Fernandes C, Barra CB. Leukocyte count, C reactive protein, alpha-1 acid glycoprotein and erythrocyte sedimentation rate in acute appendicitis. Arq Gastroenterol. 2003;40:25-30.

15. Albu E, Miller BM, Choi $Y$, et al. Diagnostic value of $C$-reactive protein in acute appendicitis. Dis Colon Rectum. 1994;37:49-51.

16. Howell JM, Eddy OL, Lukens TW, Thiessen ME, Weingart SD, Decker WW. Clinical policy: Critical issues in the evaluation and management of emergency department patients with suspected appendicitis. Ann Emerg Med. 2010;55:71-116.

17. Karamanakos SN, Sdralis E, Panagiotopoulos S, Kehagias I. Laparoscopy in the emergency setting: a retrospective review of 540 patients with acute abdominal pain. Surg Laparosc Endosc Percutan Tech. 2010;20:119-124

18. Roberts KE, Starker LF, Duffy AJ, Bell RL, Bokhari J. Stump Appendicitis: A Surgeon's Dilemma. JSLS. 2011;15:373-378.

19. Singh AK, Gervais DA, Hahn PF, Sagar P, Mueller PR, Novelline RA. Acute Epiploic Appendagitis and Its Mimics. RadioGraphics. 2005;25:1521-1534.

20. Almaramhy $\mathrm{HH}$. Acute appendicitis in young children less than 5 years: review article. Ital J Pediatr. 2017;43:15 